\title{
Corrigendum: Only the Rye Derived Part of the 1BL/1RS Hybrid Centromere Incorporates CENH3 of Wheat
}

\author{
Raheleh Karimi-Ashtiyani ${ }^{1,2 *}$, Veit Schubert ${ }^{2}$ and Andreas Houben ${ }^{2 *}$ \\ ${ }^{1}$ Department of Biotechnology, Faculty of Agriculture, Tarbiat Modares University, Tehran, Iran, ${ }^{2}$ Leibniz Institute of Plant \\ Genetics and Crop Plant Research (IPK), Gatersleben, Germany
}

Keywords: CENH3, 1BL/1RS, Robertsonian translocation, wheat, dicentric, rye, hybrid centromere

\section{A Corrigendum on}

Only the Rye Derived Part of the 1BL/1RS Hybrid Centromere Incorporates CENH3 of Wheat by Karimi-Ashtiyani, R., Schubert, V., and Houben, A. (2021). Front. Plant Sci. 12:802222. doi: 10.3389/fpls.2021.802222

\section{OPEN ACCESS}

Approved by:

Frontiers Editorial Office,

Frontiers Media SA, Switzerland

*Correspondence: Raheleh Karimi-Ashtiyani

r.karimi@modares.ac.ir Andreas Houben

houben@ipk-gatersleben.de

Specialty section:

This article was submitted to

Plant Cell Biology,

a section of the journal

Frontiers in Plant Science

Received: 14 January 2022

Accepted: 02 February 2022

Published: 04 March 2022

Citation:

Karimi-Ashtiyani R, Schubert $V$ and Houben A (2022) Corrigendum: Only the Rye Derived Part of the 1BL/1RS

Hybrid Centromere Incorporates CENH3 of Wheat.

Front. Plant Sci. 13:854911.

doi: 10.3389/fpls.2022.854911
In the original article, there was an error. The origin and history of the analysed $1 \mathrm{~B} / 1 \mathrm{R}$ hybrid centromere was not correctly described and required correction in the Abstract, Materials and Methods section, and Figure 1C.

A correction has been made to the Abstract.

The original text, "The wheat-rye 1BL/1RS translocation chromosome in the background of wheat resulted from a centric misdivision followed by the fusion of the broken arms of chromosomes $1 \mathrm{~B}$ and $1 \mathrm{R}$ from wheat and rye, respectively" has been corrected to: "A chromosome $1 \mathrm{~B}$ reconstructed in wheat by centric misdivision from two wheat-rye centric translocations is known to carry a hybrid wheat-rye centromere."

A correction has been made to the section Materials and Methods, subsection Plant Material and Cultivation, paragraph 1 :

"The $1 \mathrm{~B}_{\text {rec }}-1$ line of cv. Pavon 76 carrying a reconstructed chromosome 1B (Lukaszewski, 1993, 1997) was grown in a greenhouse at $16 \mathrm{~h}$ light, $22^{\circ} \mathrm{C}$ day $/ 16^{\circ} \mathrm{C}$ night conditions. Chromosome $1 \mathrm{~B}_{\text {rec }}-1$ was reconstructed by centric misdivision from two centric wheat-rye translocations, $1 \mathrm{RS} .1 \mathrm{BL}$ and 1BS.1RL. In essence, the chromosome itself is a centric translocation, composed of a wheat chromosome arm 1BS from cv. Pavon 76 and 1BL arm from the translocation 1RS.1BL from the Aurora/Kavkaz source (Lukaszewski, 1993, 1997). As demonstrated by Zhang et al. (2001) this chromosome carries a hybrid centromere, composed in part of a wheat centromere and in part of a rye centromere."

In the original article, there was a mistake in Figure $\mathbf{~ C}$ as published because the origin of the chromosome arms was wrongly depicted. Additionally, the origin of the analysed chromosome was wrongly described in the legend for Figure 1C. The corrected Figure 1C and its legend appears below.

The authors apologize for these errors and state that this does not change the scientific conclusions of the article in any way. The original article has been updated. 


\section{REFERENCES}

Lukaszewski, A. J. (1993). Reconstruction in wheat of complete chromosomes $1 \mathrm{~B}$ and $1 \mathrm{R}$ from the $1 \mathrm{RS} .1 \mathrm{BL}$ translocation of 'Kavkaz' origin. Genome 36, 821-824. doi: 10.1139/g 93-109

Lukaszewski, A. J. (1997). Further manipulation by centric misdivision of the 1RS.1BL translocation in wheat. Euphytica 94, 257-261. doi: 10.1023/A:1002916323085

Zhang, P., Friebe, B., Lukaszewski, A. J., and Gill, B. S. (2001). The centromere structure in Robertsonian wheat-rye translocation chromosomes indicates that centric breakage-fusion can occur at different positions within the primary constriction. Chromosoma 110, 335-344. doi: 10.1007/s00412 0100159
Publisher's Note: All claims expressed in this article are solely those of the authors and do not necessarily represent those of their affiliated organizations, or those of the publisher, the editors and the reviewers. Any product that may be evaluated in this article, or claim that may be made by its manufacturer, is not guaranteed or endorsed by the publisher.

Copyright (C) 2022 Karimi-Ashtiyani, Schubert and Houben. This is an open-access article distributed under the terms of the Creative Commons Attribution License (CC $B Y)$. The use, distribution or reproduction in other forums is permitted, provided the original author(s) and the copyright owner(s) are credited and that the original publication in this journal is cited, in accordance with accepted academic practice. No use, distribution or reproduction is permitted which does not comply with these terms. 


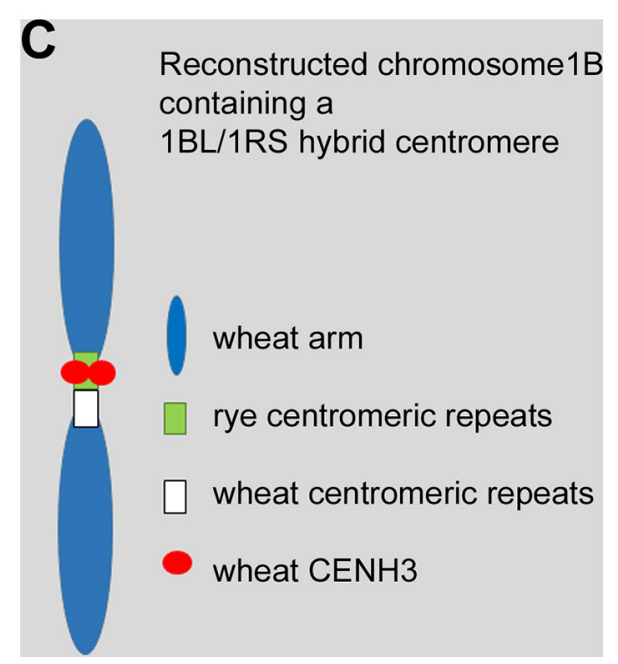

FIGURE 1 | (C) Schematic representation of the reconstructed wheat chromosome $1 \mathrm{~B}$ with a hybrid wheat-rye centromere. This centromere is composed of wheat and rye centromeric repeats. The wheat-derived CENH3 co-localized only with the rye-derived centromeric chromatin creating a functional chromosome. 